\title{
Globalization, Economic Reform, and Structural Price Transmission: SAM Decomposition Techniques with an empirical application to Vietnam
}

\author{
David Roland-Holst* \\ Mills College and RDRC \\ Finn Tarp \\ University of Copenhagen and RDRC
}

\begin{abstract}
Globalization poses special challenges for economies in transition, particularly those which have been slow to reform systems of administered prices. Such allocation mechanisms now encounter significant friction from external market forces, and it is vital for policymakers to better anticipate the incidence of external price transmission. In this paper, we propose a novel variation of multiplier decomposition methods; make use of an up-to-date social accounting matrix (SAM) for Vietnam; and demonstrate how this kind of information can help identify adverse incentive and wealth effects that might undermine reform and structural adjustments efforts in this important emerging Asian economy.
\end{abstract}

Key words: Price transmission, SAMs, multiplier decomposition, Vietnam JEL classification: C69, O21, P20

*David Roland-Holst is the James Irvine Professor of Economics at Mills College and Director of the Rural Development Research Consortium (RDRC) at the University of California, Berkeley (dwrh@rdrc.net). Finn Tarp is Professor of Development Economics and Coordinator of the Development Economics Research Group (DERG) at the University of Copenhagen (Finn.Tarp@econ.ku.dk). Opinions expressed here are those of the authors and should not be attributed to their affiliated institutions. 


\section{Introduction}

The advent of globalization and market reforms in many countries has significantly raised awareness of the mechanism of price transmission. Informal pressures arise from border prices, and more direct challenges are posed by conformity requirements in WTO negotiation and a myriad of regional trade arrangements. Individuals as well as public and private institutions have started to think about prices and markets in ways that only theoretical economists did a century ago. As economic linkages continue to proliferate, especially across international boundaries, we all become more acquainted with how markets interact with one another and how livelihoods are connected through the price system. Nevertheless, the consequences of market reform are difficult to anticipate, especially in former centrally planned economies. They used to rely on administered prices, which served a variety of policy objectives. Thus, the political economy of transition to a market economy is complex, and the lack of historical experience with price dynamics is a stumbling block in reform efforts. Better visibility for policymakers of the incidence of price transmission is clearly an important need.

In a series of seminal contributions, Pyatt and Round (1979), Defourny and Thorbecke (1984), and Round (1985) each elaborated methods of economy-wide empirical analysis based on the social accounting matrix (SAM). They have been intensively used to examine the income generating process in scores of countries, and justifiably so. ${ }^{1}$ It can also be noted that the unifying aspect of this work has been a focus on quantity-driven income determination, the primal side of the underlying accounting system. Despite their flexibility and tractability, SAMs have generally not been used to examine price transmission. This is somewhat surprising. Price formation is an essential issue in economic policy. Thus, in this paper, we propose to start filling this gap and demonstrate how a dual perspective on SAM multiplier methods can help shed light on direct and indirect price and cost linkages across an economy. We use Vietnam as case, including a new and detailed SAM estimated for the year 2000. The result is a practical framework for incidence analysis that should help improve visibility for policy makers seeking to facilitate economic reform and structural adjustment.

\footnotetext{
${ }^{1}$ SAMs have for example been used to study: (i) growth strategies in developing economies, Pyatt and Round (1985); (ii) income distribution, Pyatt and Roe (1977), and Adelman and Robinson (1978), and redistribution, Roland-Holst and Sancho (1992); (iii) fiscal policy in national or regional settings, Whalley and St. Hillaire (1983, 1987); and (iv) decomposition of activity multipliers that shed light on the circuits comprising the circular flow of income, Stone (1981), Pyatt and Round (1979), Defourny and Thorbecke (1984), and Robinson and Roland-Holst (1988).
} 
The structural perspective advocated here is of special relevance to economies with extensive price administration, and even more so when, as is the case in Vietnam, prices represent only one aspect of an extensive set of institutional rigidities. For an economy like this, which is at the early stages of both domestic and external market reform, price transmission is likely to be significant in the transition process. First, in the past factor prices did not conform to the neoclassical paradigm. They were implicitly indexed to commodity prices or cost-of-living effects, so the initial misalignment between the administered prices and their real or hypothetical market counterparts is likely to be large. Second, reforms geared at addressing institutional rigidities and market failures can be expected to facilitate transmission of price shocks rather than moderate them. These issues are of great policy relevance in economies opening up to global market forces, and even more so when they are simultaneously undertaking extensive domestic market reforms as in Vietnam. Of course, no real-world economy is purely neoclassical or purely structural, but by analyzing the structural components in isolation, we gain additional knowledge about the transmission mechanism for prices and its implications for policy and welfare.

Section 2 presents the dual formulation of the SAM multiplier models, whereas Section 3 recasts two leading decomposition techniques in this framework. They are applied in Section 4, which reveals patterns of transmission from external price shocks to domestic incomes and a variety of producer, factor, and consumer price/cost indices. Section 5 concludes.

\section{Methodology}

A standard SAM offers a disaggregate view of value flows in a given base period, detailing the direct linkages among its component sectors and institutions and pointing out the scope of the underlying indirect interactions. Inflows from exogenous sectors that stimulate the level of activity of a production sector, for instance, will also induce additional factor incomes that, once distributed among households, will be used to finance new final demand for producer goods and services. Table A1 in the Annex depicts a partitioned simplified MacroSAM with four classes or groups of accounts, namely production, factors, households, and a consolidated account of the remaining sectors (government, capital and 
foreign accounts). Columns of the SAM indicate payments and rows tally receipts. ${ }^{2}$ For each group total spending is necessarily equal to total receipts, i.e., column and row totals of the matrix are equal.

A SAM-based quantity model is derived from the SAM-table by distinguishing endogenous and exogenous groups and assuming activity levels may vary while prices are fixed. This assumption is justified in the presence of excess capacity and unused resources in production activities. Suppose group 1 is chosen as endogenous and 2, 3 and 4 are exogenous. Let $A_{i j}$ denote the matrix of normalized column coefficients obtained from $T_{i j}$ and let $v_{\mathrm{i}}$ denote that the incomes of groups $i=2,3,4$ are taken as given exogenously. Then the income level of group 1 can be expressed by:

$$
\begin{aligned}
Y_{1} & =A_{11} Y_{1}+A_{13} U_{3}+A_{14} U_{4} \\
& =\left(I-A_{11}\right)^{-1}\left(A_{13} U_{3}+A_{14} U_{4}\right)=M_{11} X
\end{aligned}
$$

where $\mathrm{M}_{11}=\left(\mathrm{I}-\mathrm{A}_{11}\right)^{-1}$ is the usual interindustry Leontief inverse and $\mathrm{x}$ is a vector of exogenous income levels. Since (1) implies $\Delta \mathrm{Y}_{1}=\mathrm{M}_{11} \Delta \mathrm{x}$, matrix $\mathrm{M}_{11}$ is also termed the multiplier matrix. Column $i$ of $\mathrm{M}_{11}$ shows the global effects on all endogenous activity levels induced by an exogenous unit inflow accruing to $i$, after allowing for all interdependent feedbacks to run their course.

Consider now the dual case, where prices are responsive to costs but not to activity levels. The justifying assumption here, in addition to the usual excess capacity condition, is generalized homogeneity and fixed coefficients in activities. This is a situation where the classical dichotomy between prices and quantities holds true and prices can be computed independently of activity levels. Let now $\mathrm{p}_{\mathrm{i}}$ denote a price index for the activity of group $i .^{3}$ With the same classification of endogenous and exogenous accounts and identical notational conventions, column 1 of the SAM yields:

$$
\mathrm{p}_{1}=\mathrm{p}_{1} \mathrm{~A}_{11}+\pi_{2} \mathrm{~A}_{21}+\pi_{4} \mathrm{~A}_{41}
$$

\footnotetext{
${ }^{2}$ Note that no flows are associated with cells $(1,2),(2,2),(2,3)$ and $(3,1)$.

${ }^{3}$ The notion of price should be taken in the same broad sense as the notion of income of a sector or institution has in a SAM framework
} 


$$
=\left(\pi_{2} \mathrm{~A}_{21}+\pi_{4} \mathrm{~A}_{41}\right)\left(\mathrm{I}-\mathrm{A}_{11}\right)^{-1}=v_{1} \mathrm{M}_{11}
$$

where $v_{1}$ is a row vector of exogenous costs (i.e., factor payments, taxes, import costs) and $\mathrm{M}_{11}$ is the same multiplier matrix as in (1). Notice that from (2) we have $\Delta \mathrm{p}_{1}=\Delta v_{1} \mathrm{M}_{11}$ so we can re-interpret the Leontief inverse by reading across rows. Row $j$ of $\mathbf{M}_{11}$ displays the effects on prices triggered by a unitary exogenous change in sector $j$ costs. This is a straightforward but seldom used interpretation of the Leontief multiplier matrix.

Starting from equation (1) of the basic linear model, SAM-based quantity models yield extensions to encompass a larger and more complete view of the income generating process. In the same way, we believe SAM-based price models departing from expression (2) may prove to be useful generalizations for evaluating the extensive cost linkages that pervade the relationships among households, factors, and producers.

To give content to this approach consider each one of these groups as undertaking an economic activity. Producers pay for raw materials $\left(T_{11}\right)$ and factors $\left(T_{21}\right)$ which are combined to generate output; factors make use of household endowments $\left(T_{32}\right)$ to provide firms with labour and capital services. Finally, households purchase output $\left(\mathrm{T}_{13}\right)$ from production to obtain consumption. ${ }^{4}$ Additionally, each group is liable to pay taxes or import costs to the consolidated group 4. In terms of taxes, the government collects indirect production taxes from firms, taxes on the use of labour and capital from factors, and indirect consumption taxes and income taxes from households. Thus, each of these activities has an implicit cost or price index, which is linked to the rest of the price indices, through the coefficient sub matrices of the SAM. However, as it stands, price expression (2) omits these linkages and falls short of a satisfactory representation of interdependencies in the economy.

These links can be coherently integrated into a model by considering the three sets of accounts comprising producers, factors and households as endogenous and taking the consolidated account as exogenous. Using the column normalized expenditure coefficients and reading down the SAM columns for endogenous accounts yields:

$$
\mathrm{p}_{1}=\mathrm{p}_{1} \mathrm{~A}_{11}+\mathrm{p}_{2} \mathrm{~A}_{21}+\pi_{4} \mathrm{~A}_{41}
$$

\footnotetext{
${ }^{4}$ Transfers among households $\mathrm{T}_{33}$ can be thought of as distribution costs linked to consumption.
} 


$$
\begin{aligned}
& \mathrm{p}_{2}=\mathrm{p}_{3} \mathrm{~A}_{32}+\pi_{4} \mathrm{~A}_{42} \\
& \mathrm{p}_{3}=\mathrm{p}_{1} \mathrm{~A}_{13}+\mathrm{p}_{3} \mathrm{~A}_{33}+\pi_{4} \mathrm{~A}_{43}
\end{aligned}
$$

Define a matrix A of normalized coefficients:

$$
A=\left[\begin{array}{ccc}
A_{11} & 0 & A_{13} \\
A_{21} & 0 & 0 \\
0 & A_{32} & A_{33}
\end{array}\right]
$$

let $\mathrm{p}=\left(\mathrm{p}_{1}, \mathrm{p}_{2}, \mathrm{p}_{3}\right)$ be the vector of prices for the endogenous sectors of the SAM, and set the vector of exogenous costs (taxes, import costs) as $v=\pi_{4} \mathrm{~A}(4)$, where $\mathrm{A}(4)$ is the sub matrix of the SAM composed by column adjoining $\mathrm{A}_{41}, \mathrm{~A}_{42}$ and $\mathrm{A}_{43}$. In matrix notation:

$$
p=p A+v=v(I-A)^{-1}=v M
$$

where $\mathrm{M}$ is the multiplier matrix. For the same classification of endogenous and exogenous accounts, $\mathrm{M}$ is also the multiplier matrix of the endogenous income determination model:

$$
\mathrm{Y}=(\mathrm{I}-\mathrm{A})^{-1} \mathrm{X}=\mathrm{Mx}
$$

The interpretation of $\mathrm{M}$ is different, however, depending on whether we read its entries across the rows or down the columns. To clarify this distinction, $\mathrm{M}$ will be referred as the (standard) multiplier matrix whereas its transpose $M$ ' will be termed the pricetransmission matrix

\section{Decomposition Methods for Price Transmission Analysis}

In this section, we reformulate two of the leading methods of multiplier decomposition analysis for application to the study of price transmission, i.e. respectively 
block (e.g. Pyatt and Round (1979), Round (1985), and Stone (1981)), and path decomposition (Defourny and Thorbecke, 1984). As in the previous section, the approach is straightforward, but using it in the present context makes it possible to elucidate price linkages in economies such as Vietnam with extensive structural and institutional rigidities in a transparent and analytically useful manner.

\subsection{Block-decomposition of Price Transmission}

In a seminal series of contributions, Stone (1981), Pyatt and Round (1979), and Round (1985) showed how the multiplier matrix $M$ can be decomposed into three economically meaningful additive (or multiplicative) components or sub-matrices. The first of these is a matrix that includes both the direct effects on the endogenous accounts of oneunit exogenous shocks (appearing as unit increases in the diagonal) and subsequent interaction effects among accounts within the same institutional group. The second component is a so-called open-loop matrix, which captures cross-effects between different institutional groups. These effects are transmitted from one category of endogenous institutions to other endogenous categories, and in turn, set in motion multiplier processes of within-category interaction effects, which amplify the initial stimulus. The third component is a closed-loop matrix, which detail the multiplier effects of an exogenous change on one institutional group, after it has travelled through the rest of endogenous accounts and returned to the original recipient. Thus, the closed-loop matrix captures the full circular multiplier effects net of own and open loop effects.

To decompose the price-transmission matrix $M^{\prime}$ let us take expression (4) and consider any matrix $\mathrm{A}^{*}$, which satisfy standard algebraic requirements. ${ }^{5}$ In can be shown that:

$$
\begin{aligned}
\mathrm{p} & =v \mathrm{M} \\
& =\mathrm{p} \mathrm{A}+\mathrm{p} \tilde{\mathrm{A}}-\mathrm{p} \tilde{\mathrm{A}}+v \\
& =\mathrm{p}(\mathrm{A}-\tilde{\mathrm{A}})(\mathrm{I}-\tilde{\mathrm{A}})^{-1}+v(\mathrm{I}-\tilde{\mathrm{A}})^{-1}=\mathrm{p} \mathrm{A}^{*}+v(\mathrm{I}-\tilde{\mathrm{A}})^{-1} \\
& =\left[\mathrm{p} \mathrm{A}^{*}+v(\mathrm{I}-\tilde{\mathrm{A}})^{-1}\right] \mathrm{A}^{*}+v(\mathrm{I}-\tilde{\mathrm{A}})^{-1}
\end{aligned}
$$

\footnotetext{
${ }^{5}$ Ã must be conformal to A and (I- Ã) must be invertible.
} 


$$
\begin{aligned}
& =\mathrm{p} \mathrm{A}^{* 2}+v(\mathrm{I}-\tilde{\mathrm{A}})^{-1}\left(\mathrm{I}+\mathrm{A}^{*}\right) \\
& =\left[\mathrm{p} \mathrm{A}^{*}+v(\mathrm{I}-\tilde{\mathrm{A}})^{-1}\right] \mathrm{A}^{*^{2}}+v(\mathrm{I}-\tilde{\mathrm{A}})^{-1}\left(\mathrm{I}+\mathrm{A}^{*}\right) \\
& =\mathrm{p} \mathrm{A}^{*^{3}}+v(\mathrm{I}-\tilde{\mathrm{A}})^{-1}\left(\mathrm{I}+\mathrm{A}^{*}+\mathrm{A}^{*^{2}}\right) \\
& =v(\mathrm{I}-\tilde{\mathrm{A}})^{-1}\left(\mathrm{I}+\mathrm{A}^{*}+\mathrm{A}^{*^{2}}\right)\left(\mathrm{I}-\mathrm{A}^{*^{3}}\right)^{-1} \\
& =v \mathrm{M}_{1} \mathrm{M}_{2} \mathrm{M}_{3}
\end{aligned}
$$

To obtain the corresponding decomposition $\mathrm{M}^{\prime}=\mathrm{M}_{3}{ }^{\prime} \mathrm{M}_{2}{ }^{\prime} \mathrm{M}_{1}{ }^{\prime}$, we extract from matrix A the blocks $\mathrm{A}_{11}$ and $\mathrm{A}_{33}$ and take:

$$
\tilde{A}=\left[\begin{array}{ccc}
A_{11} & 0 & 0 \\
0 & 0 & 0 \\
0 & 0 & A_{33}
\end{array}\right]
$$

This yields:

$$
\begin{aligned}
& \mathrm{M}_{1}^{\prime}=\left[\begin{array}{ccc}
\left(\mathrm{I}-\mathrm{A}_{11}\right)^{-1} & 0 & 0 \\
0 & \mathrm{I} & 0 \\
0 & 0 & \left(\mathrm{I}-\mathrm{A}_{33}\right)^{-1}
\end{array}\right] \\
& M^{\prime}{ }_{2}=\left[\begin{array}{ccc}
\mathrm{I} & \mathrm{A}^{*}{ }_{21} & \mathrm{~A}_{32}^{*} \mathrm{~A}^{*}{ }_{21} \\
\mathrm{~A}^{*}{ }_{13} \mathrm{~A}^{*}{ }_{32} & \mathrm{I} & \mathrm{A}^{*}{ }_{32} \\
\mathrm{~A}^{*}{ }_{13} & \mathrm{~A}^{*}{ }_{21} \mathrm{~A}^{*} & \mathrm{I}
\end{array}\right] \\
& \mathrm{M}_{3}^{\prime}=\left[\begin{array}{ccc}
\left(\mathrm{I}-\mathrm{A}{ }_{13} \mathrm{~A}_{32}^{*} \mathrm{~A}_{21}^{*}\right)^{-1} & 0 & 0 \\
0 & \left(\mathrm{I}-\mathrm{A}_{21}^{*} \mathrm{~A}_{13}^{*} \mathrm{~A}_{32}^{*}\right)^{-1} & 0 \\
0 & 0 & \left(\mathrm{I}-\mathrm{A}^{*}{ }_{32} \mathrm{~A}_{21}^{*} \mathrm{~A}_{13}^{*}\right)^{-1}
\end{array}\right]
\end{aligned}
$$

with $A^{*}{ }_{13}=A_{13}\left(I-A_{33}\right)^{-1}, A^{*}{ }_{21}=A_{21}\left(I-A_{11}\right)^{-1}, A^{*}{ }_{32}=A_{32}$.

The first column of the multiplicative transfer matrix $\mathrm{M}_{1}{ }_{1}$ shows how an exogenous cost increase affecting the production activities multiplies itself through the interindustry cost 
linkages (Leontief inverse) but exerts no effects on groups 2 and 3. In contrast, the first column of the open-loop matrix $\mathrm{M}_{2}{ }_{2}$ indicates how the same exogenous cost increase ends up having an impact on factors (second entry, $A *{ }_{13} A *{ }_{32}$ ) after rebounding from households (third entry, $A^{*}{ }_{13}$ ). Finally, the first column of the closed-loop matrix $\mathrm{M}_{3}$ captures the impact on production prices of the exogenous increase in producer costs after first affecting household cost indices $\left(\mathrm{A}^{*}{ }_{13}\right)$, then moving onto factors $\left(\mathrm{A}^{*}{ }_{13} \mathrm{~A}^{*}{ }_{32}\right)$ and from these back to producers $\left(\mathrm{A}^{*}{ }_{13} \mathrm{~A}{ }_{32} \mathrm{~A}{ }^{*}{ }_{21}\right)$. The final figure shows the overall impact after this process has converged.

Any given element of the price-transmission matrix $M$ ' can be studied using either multiplicative or additive decomposition, which yield the same information in a different format. In a general disaggregate SAM, $n+m$ individualized sectors are detailed, $n$ being taken as endogenous and $m$ exogenous. Let $I$ and $J$ denote the indexing sets for the exogenous and endogenous accounts respectively. From (4) above, and $i \in I, j \in J$, the individual impact on price $p_{j}$ of an exogenous cost change in sector $i$ can be written as:

$$
\frac{\partial p_{j}}{\partial v_{i}}=m_{j i}=1+n_{j i}^{1}+n_{j i}^{2}+n_{j i}^{3}
$$

where $m_{j i} \in \mathrm{M}^{\prime}$ and $n_{j i}^{1}, n_{j i}^{2}$, and $n_{j i}^{3}$ are elements of the additive component matrices:

$$
\begin{aligned}
& \mathrm{N}_{1}=\mathrm{M}_{1} \\
& \mathrm{~N}_{2}=\left(\mathrm{M}_{2}-\mathrm{I}\right) \mathrm{M}_{1} \\
& \mathrm{~N}_{3}=\left(\mathrm{M}_{3}-\mathrm{I}\right) \mathrm{M}_{2} \mathrm{M}_{1}
\end{aligned}
$$

which together satisfy $\mathrm{M}=\mathrm{N}_{1}+\mathrm{N}_{2}+\mathrm{N}_{3}$.

\subsection{Path-decomposition of Price Transmission}

The previous section shows that the SAM offers a convenient structure for detailed examination of price transmission. Prices can be computed and, furthermore, price changes can be decomposed according to three different categories of interdependence, which provide a detailed view of the extent and magnitude of cost-linkages as they work their way through 
the economic system. To obtain a more comprehensive description of the effect of linkages on prices, however, we need to go one step further and analyze intersectoral linkages between individual accounts of the SAM by identifying the paths along which price/cost effects travel. The structural path analysis put forth by Defourny and Thorbecke (1984) showed the rich information structure that can be derived using this approach in a SAM framework. The use of path analysis to investigate cost-linkages is a natural extension and a promising way to enrich our understanding of the price formation mechanism.

Following the ideas in the contributions of these authors, we now use the concept of structural analysis in the SAM-based price model. Each pair $\langle i, j>$ of indices in the SAM accounts is called an arc. A path is a sequence $s$ of indices $s=\langle i, k, l, \ldots, m, j\rangle$ which can be decomposed into consecutive arcs $\langle i, k>,<k, l>, \ldots,<m, j\rangle$. A path with non-repeating indices is termed an elementary path. A circuit of influence is a path $s$ where the first and last indices coincide. The influence of account $i$ on account $j$ through a path $s$ is represented by $(i \rightarrow j)_{s}$. To estimate the cost influence of account $i$ on account $j$ along $<i, j>$, notice from (4) above that, prior to any of the ensuing general equilibrium feedbacks, we have:

$$
\frac{\partial p_{j}}{\partial p_{i}}=a_{j i}
$$

Thus any exogenous price increase affecting $p_{i}$ gives rise to a direct price increase in $j$ measured by entry $(j, i)$ of the transpose of the column normalized matrix A. Due to the linear structure of the model, the direct price influence along an elementary path $s=<i, k, \ldots, m, j\rangle$ is the composite effect of the direct influences along the constituent arcs, i.e.:

$$
D_{(i \rightarrow j) s}^{p}=a_{k i} \ldots a_{j m}
$$

In any given path $s$ there may exist feedback effects among its indices. Account $i$ influences $k$ but $k$ in turn may influence $i$, either directly or through other intermediary indices. Accounts influence themselves through loops as well. All of these feedback effects taking place along circuits in the path work to amplify the magnitude of the direct influence 
being transmitted over the path. The expanded influence will be called total price influence, the ratio of total to direct price influence being the price path-multiplier:

$$
T_{(i \rightarrow j) s}^{p}=D \underset{(i \rightarrow j) s}{p} \mu_{s}^{p}
$$

Notice, on the other hand, that more than one elementary path, each one with its respective feedback circuits, may span two indices $i, j$. Therefore the total price influence along a path does not capture the full or global price influence in the network of itineraries linking $i$ and $j$. Let $S=\{s / i, j\}$ be the set of all elementary paths joining $i$ and $j$. By additivity, the global price influence is defined as:

$$
G_{(i \rightarrow j) s}^{p}=\sum_{s \in S} T_{(i \rightarrow j) s}^{p}=\sum_{s \in S} D_{(i \rightarrow j) s}^{p} \mu_{s}^{p}
$$

The last equality, where $m_{\mathrm{ji}}$ is the $(j, i)$ entry in the price-transmission matrix $\mathbf{M}^{\prime}$, follows from the fact that $S$ includes all connecting paths between accounts $i$ and $j$. Direct, total and global price influence are three distinct but related concepts of influence that supply precise information on the transmission mechanism underlying price formation.

\section{Estimates of Price Transmission for Vietnam}

In this section, we apply our methodology to Vietnam, noting that there are at present significant disparities between domestic and external prices. For this reason, market based price transmission is likely to have extensive effects on future patterns of income and economic incentives, and policy makers need as already alluded to more detailed understanding of this kind of economic incidence to anticipate adjustment problems.

The SAM used here was developed in a separate research programme. It is very detailed and was calibrated to data for $2000 .^{6}$ Among other things, the SAM includes 97 activities/commodities, 14 factors of production (12 labour types, land, and capital), and 16

\footnotetext{
${ }^{6}$ See Tarp, Roland-Holst, Rand and Jensen (2002).
} 
different household groups. Taken together, this table can elucidate very detailed incidence patterns, including a wide variety of producer, factor, and consumer price and cost index effects. ${ }^{7}$ To keep present discussion manageable, we illustrate our approach with a 30 sector, eight factor, eight household aggregation of the Vietnam SAM.

The empirical interpretation of any given multiplier element $m_{\mathrm{ji}}$ in the matrix $\mathrm{M}^{\prime}$ is quite straightforward if we take into account that benchmark prices are all calibrated to unity. Thus, $m_{\mathrm{ji}}$ gives us both the absolute and percentage variation of price $j$ when the exogenous cost in sector $i$ increases by one money unit, and the same considerations apply to any of the elements of a given decomposition. The multiplier matrix in itself is of some interest since it yields information on questions such as how a one Dong increase in taxes (production, consumption, and factor taxes, as well as tariffs) will raise producer prices, factor prices and individual cost-of-living indices. As such it provides useful information on the distortionary effects of taxes but also, and equally important, about the welfare effects on individual consumers as measured by changes in their expenditures. Tables 4.1 and 4.2 present a selection of the price decomposition results. ${ }^{8}$

\subsection{Block-decomposition of Price Multipliers}

Table 4.1 focuses on the additive block-decomposition of the price multiplier matrix, which reveals the extent to which price effects can be traced from commodity prices across the economy, grouping effects by generic structural components (production, factors, and households). The examples show the decomposition of a unitary increase in the exogenous (column) commodity or production cost and the induced effects on downstream (row) producer, factor, and consumer price indexes.

\footnotetext{
${ }^{7}$ All the accounts are listed in the Annex.

${ }^{8}$ The complete empirical results are available from the authors.
} 
Table 4.1: Block Decomposition Results for Price Transmission (all figures in percent)

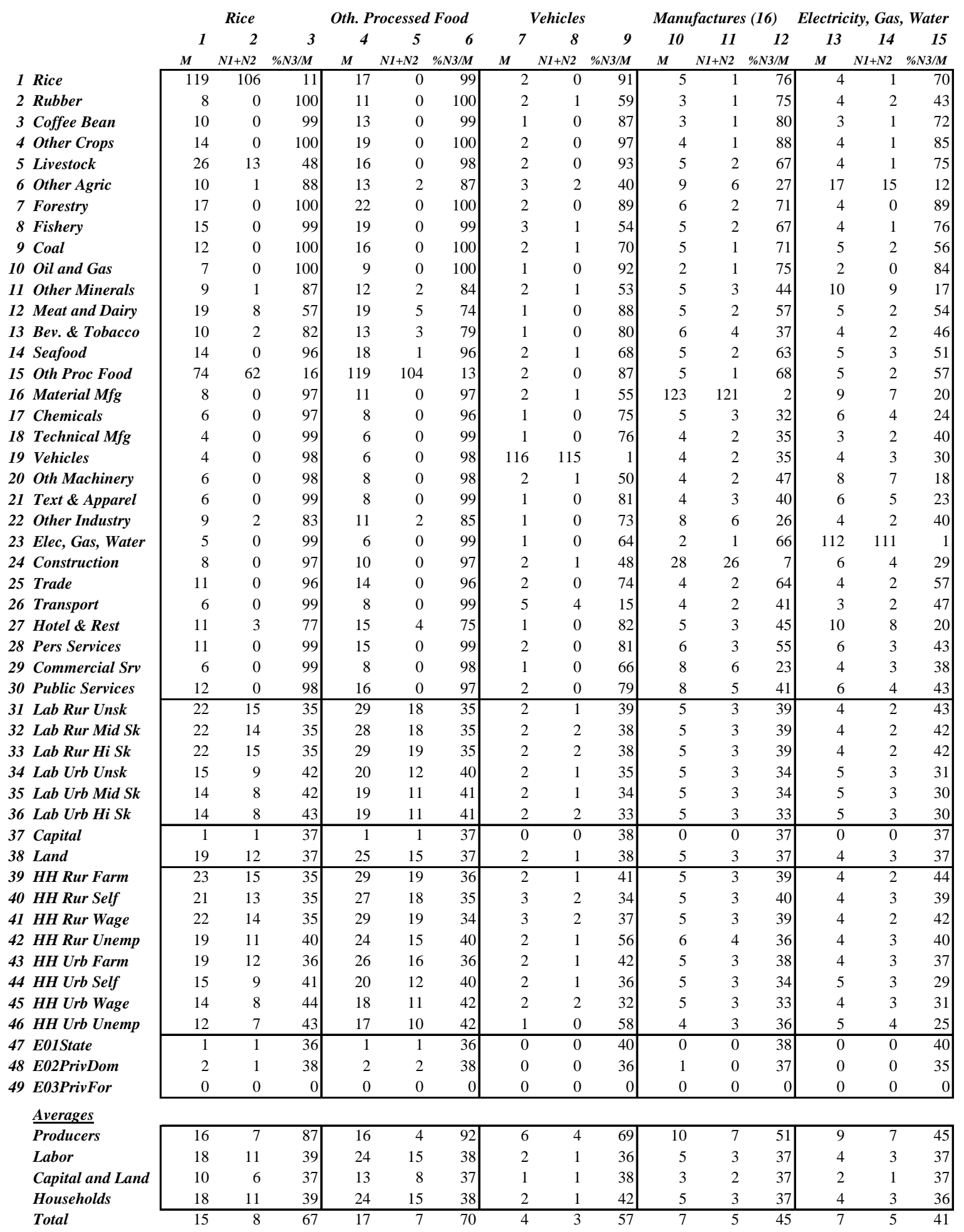


We look at five sample sectors, Rice, Other Processed Food, Vehicles, Manufactures, and Utilities. For each sector, three block components are represented: total multiplier effect (M), effect due to direct $\left(\mathrm{N}_{1}\right)$ and open loop $\left(\mathrm{N}_{2}\right)$ linkages, ${ }^{9}$ and percent of closed loop effects in the total. The last item is particularly revealing, since it indicates something more like a general equilibrium transmission effect, incorporating the longer chains of price linkage that might not be discernable to casual observers.

The most arresting features of these results are three. Firstly, indirect price transmission is a very important component of the price adjustment process. Open loop effects average between 41 and $72 \%$ of total price effects, depending on the sector considered. This fact is hardly surprising, since direct linkages are relatively weak in this economy, but it certainly highlights the challenge facing policy makers who try to anticipate induced price and cost incidence of taxes, terms of trade shifts, and effects of exchange rate policy. Relying on intuition or rules of thumb alone in this context is very unlikely to achieve something approaching optimality.

The results for subsistence and processed foods are variegated. Outside the food sector, factor and consumer price indices, the transmission of food cost inflation is mostly indirect. Other sectors see producer prices rising only in response to induced factor cost indices and some longer chain intermediate linkages. For factors and households, the effects are of course more direct but, importantly, the implied inflation elasticities are relatively high. Households experience an (unweighted) average CPI increase equal to about $18 \%$ of any increase in rice prices, with the exact effect depending on the location and factor content of the household. The result for processed food is even more dramatic, stepping up household consumption costs by $24 \%$. These results highlight the importance of food price stability to the economy. It is also noteworthy that about $40 \%$ of the inflation transmission from food prices to households is indirect, arising from open loop linkages.

A second striking feature of these results is the relatively low levels of inflation transmission in essential sectors associated with economic modernization: vehicles, manufactures, and utilities. In all three categories, average inflation elasticities are less than 7\%. This result is due primarily to Vietnam's early stage of development, still primarily agrarian and highly subsistence oriented. For this reason, the proportions of domestic cost

\footnotetext{
${ }^{9}$ Note that nonzero elements in the matrices $N_{1}$ and $N_{2}$ do not overlap, so they can be added without loss of structural information.
} 
and expenditure allocated to manufactures and utilities are still relatively small, especially in the context of economywide household consumption. For this reason, one might infer that the economy can tolerate significant price deregulation, exchange rate depreciation, and increased imports of manufactures, particularly if the latter take the form of capital goods and other products that contribute to accelerated productivity, growth, and modernization.

\subsection{Path Decomposition of Price Multipliers}

The price-transmission matrix $M$ ' gives a tableau presentation of composite effects across the economy, but the true incidence of price transmission can only be ascertained by decomposing the detailed paths of influence that arise from expenditure linkages. This kind of detailed structural analysis is exactly the purpose of path decomposition, and we apply this analysis to the Vietnamese economy with a few examples from the 2000 SAM.

Tables 4.2-4.4 below show detailed chains of price transmission from products to producers, producers to households, and factors to households. In each case, we examine constituent chains of up to five institutions, contributing up to .001 of the total transmission effect $m_{j i}$ in the price transmission matrix $M^{\prime}$. Each table lists the global effect $\left(m_{j i}\right)$, the component (Total) effect along the constituent path specified, and the marginal and cumulative percentages of the total effect, respectively.

Table 4.2 focuses on links between producer prices. Generally speaking, the current stage of Vietnam's economic development is characterized by fairly low levels of sectoral articulation, and thus producer to producer price transmission is fairly direct. To illustrate this, we give examples of the effects of rising Rice prices on Other Food Products and the effects of rising utility costs on Other Agriculture and heavy Manufacturing (MatMfg). In the first case, rice price increases are about 74\% passed through to Other Processed Food. The vast majority of this effect comes directly from intermediate use of unprocessed rice, and represents the huge rice polishing mill industry. A very small contribution also arises from links through consumption (Rural Households) and factor payments (Rural Unskilled Labor).

Other Agriculture, which includes most irrigated specialty crops, is the most utilityintensive agricultural sector in Vietnam at present. For this reason, price increases in utilities are passed on directly (84\% of global effects), but modestly (an elasticity of .166). About 3\% more of the global effect is transmitted though intermediate goods (Manufactures and 
Machinery) and consumption linkages. In the case of Manufacturing, indirect linkages are somewhat more important because this relatively modern sector is more highly articulated to other sectors. Despite this fact, inflation transmission from utilities is very subdued, with an elasticity of only .086. About three fourths of this global effect is accounted for by direct links and trilateral links via two other upstream sectors (minerals and trade).

\section{Table 4.2: Path Linkages from Products to Producers}

\begin{tabular}{|c|c|c|c|c|}
\hline Path $^{10}$ & $\begin{array}{r}\text { Global } \\
\text { Effect }\end{array}$ & $\begin{array}{l}\text { Total } \\
\text { Effect }\end{array}$ & $\begin{array}{l}\% \text { of } \\
\text { lobal }\end{array}$ & $\begin{array}{r}\text { Cum } \\
\% \\
\end{array}$ \\
\hline A15OtPrFd<-A01Rice & 0.737 & 0.727 & 98.7 & 98.7 \\
\hline A15OtPrFd<-L01RU<-HH01RF<-A01Rice & & 0.001 & 0.2 & 98.8 \\
\hline A06OthAg<-A23ElGsWat & 0.166 & 0.139 & 84.0 & 84.0 \\
\hline A06OthAg<-A16MatMfg<-A23ElGsWat & & 0.002 & 1.4 & 85.4 \\
\hline A06OthAg $<-$ A20OthMach<-A23ElGsWat & & 0.001 & 0.7 & 86.1 \\
\hline 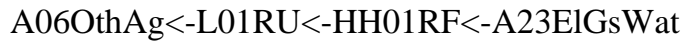 & & 0.001 & 0.7 & 86.8 \\
\hline A16MatMfg<-A23ElGsWat & 0.086 & 0.059 & 68.0 & 68.0 \\
\hline A16MatMfg<-A11OthMin<-A23ElGsWat & & 0.006 & 7.2 & 75.2 \\
\hline A16MatMfg<-A25Trade<-A23ElGsWat & & 0.001 & 1.3 & 76.5 \\
\hline
\end{tabular}

Table 4.3 gives examples of the impact of producer price changes on Vietnamese households. In this case, we focus on Urban Wage earning households, a group most sensitive to the consumption effects of changes in market prices. For the sake of comparison, we examine changes in two essential commodity prices, Rice and Processed Food. Because they are removed from the subsistence sector, this consumer group is more likely to feel the brunt of changing market prices and to be more import dependent. This makes it especially important for policy makers to understand and anticipate the incidence of price transmission to this group. Despite the very direct linkage between producer prices for these two goods (Table 4.2), we see more complex patterns emerging in consumer price index effects.

In light of the importance of this group to the economy in terms of growth and modernization, it is perhaps fortunate that their inflation elasticities for essential and basic foodstuffs are relatively low, .136 and .184 for Rice and Processed Food, respectively. Not only are these relatively modest, but they are propagated through fairly long price transmission chains. In the case of Rice, the main effect of course results after the rice is polished, and 55\% of the global effect comes through the Other Food Processing sector.

\footnotetext{
${ }^{10}$ Sector labels are defined in the Appendix.
} 
Beyond this, the other prominent transmission paths include feed (Livestock), beverages, restaurants, and a variety of consumption linkages.

Table 4.3: Path Linkages from Producers to Households

\begin{tabular}{|c|c|c|c|c|}
\hline Path & $\begin{array}{r}\text { Global } \\
\text { Effect } \\
\end{array}$ & $\begin{array}{c}\text { Total } \\
\text { EffectG }\end{array}$ & $\begin{array}{l}\% \text { of } \\
\text { lobal }\end{array}$ & $\begin{array}{r}\text { Cum } \\
\% \\
\end{array}$ \\
\hline HH07UW<-A01Rice & 0.136 & 0.007 & 5.2 & 5.2 \\
\hline HH07UW<-A05LivStk<-A01Rice & & 0.008 & 6.1 & 11.2 \\
\hline HH07UW<-A15OtPrFd<-A01Rice & & 0.076 & 55.7 & 66.9 \\
\hline HH07UW<-A12MtDary<-A05LivStk<-A01Rice & & 0.001 & 0.7 & 67.6 \\
\hline HH07UW<-A13BevTob<-A15OtPrFd<-A01Rice & & 0.001 & 0.6 & 68.2 \\
\hline HH07UW<-A27HotRest<-A15OtPrFd<-A01Rice & & 0.001 & 1.0 & 69.2 \\
\hline HH07UW $<$-A04OthCrp $<-$ L01RU $<-$ HH01RF $<$-A15OtPrFd $<-$ & A01Rice & 0.001 & 0.7 & 69.9 \\
\hline HH07UW $<-$ A05LivStk $<-$ L01RU $<-$ HH01RF $<-$ A15OtPrFd $<-$ A & A01Rice & 0.001 & 0.6 & 70.5 \\
\hline HH07UW $<-$ A30PubServ $<-$ L01RU $<-$ HH01RF $<$-A15OtPrFd $<-$ & -A01Rice & 0.002 & 1.7 & 72.2 \\
\hline & 0.184 & & 68.1 & \\
\hline HH07UW<-A12MtDary<-A15OtPrFd & & 0.001 & 0.5 & 68.5 \\
\hline HH07UW<-A13BevTob<-A15OtPrFd & & & 0.7 & 59.3 \\
\hline HH07UW <-A27HotRest<-A15OtPrFd & & 0.002 & 1.2 & 70.5 \\
\hline HH07UW $<-$ A04OthCrp $<-$ L01RU $<-$ HH01RF $<$ & & 0.002 & 0.8 & 71. \\
\hline HH07UW $<$-A05LivStk $<-$ L01RU $<-$ HH01RF $<-$ A15OtPrFd & & 0.001 & 0.8 & 72.1 \\
\hline HH07UW<-A05LivStk<-L04UU<-HH06US<-A15OtPrFd & & 0.001 & 0.4 & 72.5 \\
\hline HH07UW<-A08Fishry<-L01RU<-HH01RF<-A15OtPrFd & & 0.001 & 0.8 & 73.3 \\
\hline HH07UW <-A13BevTob<-L01RU<-HH01RF<-A15OtPrFd & & 0.001 & 0.5 & 73.8 \\
\hline HH07UW<-A25Trade<-L01RU<-HH01RF<-A15OtPrFd & & 0.001 & 0.7 & 74.5 \\
\hline HH07UW<-A27HotRest<-L01RU<-HH01RF<-A15OtPrFd & & 0.001 & 0.5 & 75. \\
\hline HH07UW <-A29ComServ<-L01RU<-HH01RF<-A15OtPrFd & & & 0.6 & 75.5 \\
\hline HH07UW<-A30PubServ<-L01RU<-HH01RF<-A15OtPrFd & & 0.004 & 2.2 & 77.7 \\
\hline HH07UW $<-$ A30PubServ $<-$ L01RU $<-$ HH02RS $<$-A15OtPrFd & & 0.001 & 0.5 & 78. \\
\hline
\end{tabular}

Other processed food hits the CPI of urban wage earners even more directly, with $68.1 \%$ of the global effect, followed by upstream links to other consumables (Meat and Dairy, Beverages and Tobacco, and Restaurants). Finally, an extended series of consumption linkages accounts for about $10 \%$ of the global effect. These generally extend from consumption of Other Food Processing goods by most household groups, then to factor price inflation in urban consumption goods.

Final examples of path decomposition examine the composition of pass though effects from factor markets to households. In this case, we examine how the CPI can be affected by rising prices for nonhuman factors of production, capital and land. In an economy, undertaking a very dynamic transition from low-income levels, both these cost components can exert significant but complex influences on real living standards. 
Table 4.4 indicates how the cost components affect the consumption weighted purchasing power of another essential constituency, the majority Vietnamese population of rural farmers. Capital price increases have a rather significant effect on these households, especially considering their relatively weak links to the market economy. A unitary increase in capital costs raises the market CPI of Rural Farmers by .20, a magnitude that should arouse concern in the minds of policy makers. This is particularly the case for Vietnam, which is at the earliest stages of agricultural mechanization and technology induced productivity growth.

Just as interesting, however, is the complexity of the transmission process. A total of 28 paths must be delineated to identify only 58\% of the global effect, and individual path contributions are much more uniform than in previous examples. Having said this, it should be emphasized that these effects are coming mainly through the household consumption function, and assume a unitary increase in some abstract composite capital good. In reality, prices of different types of capital may change at different rates and even different directions, changing the composition of these effects. Our estimates do indicate, however, that any significant shift in the aggregate factor terms of trade could have important consequences for rural households.

The case of land is somewhat simpler, and considerably more moderate in terms of inflation transmission. Land prices have substantial influence on Rural Households only by their effect on producer prices of agricultural goods and downstream processed foods. In total, the elasticity of the Rural Farm CPI with respect to land cost is only .09, indicating that this factor is still relatively minor in its contribution to living costs. 
Table 4.4: Path Linkages from Factors to Households

\begin{tabular}{|c|c|c|c|c|}
\hline Path & $\begin{array}{r}\text { Global } \\
\text { Effect }\end{array}$ & $\begin{array}{c}\text { Total } \\
\text { Effect }\end{array}$ & & $\begin{array}{r}\text { Cum } \\
\% \\
\end{array}$ \\
\hline HH01RF $<$-A01Rice $<$-Capital & 0.191 & 0.001 & 0.5 & 0.5 \\
\hline HH01RF $<-$ A04OthCrp $<-$-Capital & & 0.002 & 1.3 & 1.8 \\
\hline HH01RF<-A05LivStk<-Capital & & 0.003 & 1.6 & 3.4 \\
\hline HH01RF<-A08Fishry<-Capital & & 0.003 & 1.8 & 5.2 \\
\hline HH01RF $<-$ A13BevTob $<$-Capital & & 0.015 & 7.7 & 12.9 \\
\hline HH01RF<-A15OtPrFd<-Capital & & 0.012 & 6.2 & 19.1 \\
\hline HH01RF $<-$ A16MatMfg<-Capital & & 0.003 & 1.4 & 20.5 \\
\hline HH01RF<-A17Chemcl<-Capital & & 0.001 & 0.5 & 21.0 \\
\hline HH01RF $<-$ A18TechMfg $<$-Capital & & 0.001 & 0.4 & 21.4 \\
\hline HH01RF<-A21TxtAprl<-Capital & & 0.003 & 1.6 & 23.0 \\
\hline HH01RF<-A22OthInd<-Capital & & 0.003 & 1.4 & 24.4 \\
\hline HH01RF $<-$ A23ElGsWat $<$-Capital & & 0.003 & 1.5 & 25.8 \\
\hline HH01RF<-A25Trade<-Capital & & 0.009 & 5.0 & 30.8 \\
\hline HH01RF<-A26Transp<-Capital & & 0.005 & 2.5 & 33.4 \\
\hline HH01RF $<$-A27HotRest $<$-Capital & & 0.003 & 1.4 & 34.7 \\
\hline HH01RF $<-$ A28PerServ $<$-Capital & & 0.004 & 2.2 & 37.0 \\
\hline HH01RF $<-$ A29ComServ $<$-Capital & & 0.018 & 9.5 & 46.4 \\
\hline HH01RF<-A30PubServ<-Capital & & 0.005 & 2.4 & 48.8 \\
\hline HH01RF $<$-A05LivStk $<-$ A22OthInd $<$-Capital & & 0.001 & 0.5 & 49.3 \\
\hline HH01RF<-A05LivStk<-A25Trade<-Capital & & 0.001 & 0.5 & 49.8 \\
\hline HH01RF $<-$ A15OtPrFd $<-$ A01Rice $<-$-Capital & & 0.003 & 1.8 & 51.6 \\
\hline HH01RF $<$-A15OtPrFd $<$-A23ElGsWat $<$-Capital & & 0.001 & 0.4 & 52.0 \\
\hline HH01RF $<-$ A15OtPrFd $<$-A25Trade $<$-Capital & & 0.006 & 3.2 & 55.2 \\
\hline HH01RF<-A25Trade<-A29ComServ<-Capital & & 0.001 & 0.4 & 55.6 \\
\hline HH01RF $<-$ A30PubServ $<-$ A23ElGsWat $<-$ Capital & & 0.001 & 0.6 & 56.2 \\
\hline HH01RF<-A30PubServ<-A29ComServ<-Capital & & 0.002 & 1.1 & 57.3 \\
\hline HH01RF $<$-A15OtPrFd $<$-A01Rice $<$-A06OthAg $<-$-Capital & & 0.001 & 0.4 & 57.7 \\
\hline HH01RF $<$-A15OtPrFd $<$-A01Rice $<$-A25Trade $<$-Capital & & 0.001 & 0.5 & 58.2 \\
\hline HH01RF $<$-A01Rice $<$-Land & 0.060 & 0.006 & 10.5 & 10.5 \\
\hline HH01RF $<-$ A04OthCrp $<$-Land & & 0.012 & 20.7 & 31.2 \\
\hline HH01RF $<-$ A05LivStk $<$-Land & & 0.002 & 3.1 & 34.3 \\
\hline HH01RF<-A05LivStk<-A01Rice<-Land & & 0.002 & 3.4 & 37.8 \\
\hline HH01RF $<-$ A05LivStk $<$-A04OthCrp $<$-Land & & 0.001 & 1.7 & 39.5 \\
\hline HH01RF $<-$ A13BevTob $<-$ A04OthCrp $<-$ Land & & 0.001 & 1.4 & 40.8 \\
\hline HH01RF $<-$ A15OtPrFd $<$-A01Rice $<$-Land & & 0.023 & 38.8 & 79.6 \\
\hline HH01RF $<-$ A15OtPrFd $<-$ A04OthCrp $<-$ Land & & 0.002 & 3.2 & 82.8 \\
\hline
\end{tabular}




\section{Conclusions}

In this paper we presented a novel way of examining the detailed structure of economy wide price transmission, which was applied to an important emerging Asian economy. Building on the seminal work of other contributors to the social accounting matrix literature, we used a SAM framework to elucidate the mechanism of price formation in the presence of endogenous factor prices and household cost-of-living adjustments. Despite its limitations compared to general equilibrium models models with endogenous activity levels, the SAM-based price model has some distinct advantages, including transparency and the ability to estimate absolute price variations, providing information of immediate use to policy makers. Furthermore, price variations can be decomposed to reveal the underlying patterns of economic interdependence and price transmission. By partitioning the SAM accounts into blocks, and adapting decomposition techniques developed for SAMs, the analyst can distinguish the extent of price effects explained by interindustry linkages, the consumption expenditures of households, and factor prices.

The linear structure of the SAM price model also allows us to break down the pricetransmission matrix with structural path decomposition techniques. Path analysis discloses in detail the network of path transmission paths and produces direct estimates of all the linkages connecting two SAM accounts. The information indicates what sectors are more cost responsive to changes taking place elsewhere in the economy. Not all sectors are equally responsive in magnitude and scope, and by identifying them in detail more informed policies, such as changes in tax rates, could be designed to minimize undesirable welfare distortions.

In sum, the use of a price model of the kind presented in this paper is especially relevant to economies in transition, where price formation is heavily affected by rigidities in factor and other prices. In Vietnam, extensive state enterprise participation and systems of national, regional, and local price administration inhibit price transmission in ways that lead to significant distortions. Moreover, the key advantage of the methodology out forward is that it can help policy makers measure the adjustment burdens that such distortions imply and elucidate the detailed paths that eventual adjustments will take, helping to more clearly identify affected groups and implement mitigating policies. 


\section{References}

Adelman, I. and Robinson, S. (1978). Income Distribution Policy in Developing Countries: A Case Study of Korea, Stanford, CA: Stanford University Press.

Defourny, J. and Thorbecke, E. (1984). 'Structural Path Analysis and Multiplier Decomposition within a Social Accounting Matrix’, Economic Journal, vol. 94, pp. 111-136.

Pyatt, G. (1988). ‘A SAM Approach to Modeling’. Journal of Policy Modeling, vol. 10, pp. 327-352.

Pyatt, G. and Roe, J. (1977). Social Accounting for Development Planning. Cambridge University Press.

Pyatt, G. and Round, J. (1979). 'Accounting and Fixed Price Multipliers in a Social Accounting Matrix’. Economic Journal, vol. 89, pp. 850-873.

Pyatt, G. and Round, J. (eds.) (1985). Social Accounting Matrices : A Basis for Planning (eds). Washington, DC: The World Bank.

Robinson, S. and Roland-Holst, D. (1988). 'Macroeconomic Structure and Computable General Equilibrium Models’. Journal of Policy Modeling, vol. 10, pp. 353-75.

Roland-Holst, D. and Sancho, F. (1992). 'Relative Income Determination in the United States: A Social Accounting Perspective'. Review of Income and Wealth, vol. 38, pp. 311-27.

Round, Jeffrey I. (1985). 'Decomposing Multipliers for Economic Systems Involving Regional and World Trade’. Economic Journal, vol. 95, pp. 383-99.

Whalley, J. and St. Hillaire, F. (1983). 'A Microconsistent Equilibrium Data Set for Canada for Use in Tax Policy Analysis’. Review of Income and Wealth, vol. 29, pp. 175-204.

Whalley, J. and St. Hillaire, F. (1987). 'A Microconsistent Data Set for Canada for Use in Regional General Equilibrium Policy Analysis’. Review of Income and Wealth, vol. 33, pp. 327-343.

Stone, R. (1981). Aspects of Economic and Social Modelling. Geneva: Librairie Droz.

Tarp, F., , Roland-Holst, D., Rand, J. and Jensen, H. T. (2002). 'A 2000 Social Accounting Matrix for Vietnam', CIEM, Hanoi. 


\section{Annex}

Table A1: A MacroSAM with Four Accounts

$\begin{array}{lccccc} & \text { I } & \text { II } & \text { III } & \text { IV } & \text { V } \\ \text { I. Production } & T_{11} & O & T_{13} & T_{14} & Y_{1} \\ \text { II. Factors } & T_{21} & O & O & T_{24} & Y_{2} \\ \text { III. Households } & O & T_{32} & T_{33} & T_{34} & Y_{3} \\ \text { IV. Rest } & T_{41} & T_{42} & T_{43} & T_{44} & Y_{4} \\ \text { V. Total } & Y_{1} & Y_{2} & Y_{3} & Y_{4} & \end{array}$


Table A2: Endogenous Institutions from the 2000 Vietnam SAM

\begin{tabular}{|c|c|c|}
\hline No. & SAM L abel & Definition \\
\hline 1 & A01Rice & Rice \\
\hline 2 & A $02 R$ ubber & Rubber \\
\hline 3 & A03Coffee & Coffee Bean \\
\hline 4 & A 040 thCrp & Other Crops \\
\hline 5 & A 05 LivStk & Livestock \\
\hline 6 & A $060 \operatorname{th} A g$ & Other Agric \\
\hline 7 & A 07 Forest & Forestry \\
\hline 8 & A 08 F ishry & Fishery \\
\hline 9 & A O9Coal & Coal \\
\hline 10 & A100 ilgas & O il and Gas \\
\hline 11 & A 110 th $M$ in & Other $M$ inerals \\
\hline 12 & A $12 M$ tDary & Meat and Dairy \\
\hline 13 & A 13 BevTob & Bev. \& Tobacco \\
\hline 14 & A 14 Seafood & Seafood \\
\hline 15 & A 150 tPrFd & Oth Proc Food \\
\hline 16 & A $16 M$ at $M f g$ & Material $M f g$ \\
\hline 17 & A17Chemcl & Chemicals \\
\hline 18 & A $18 \mathrm{Tech} M \mathrm{fg}$ & Technical Mfg \\
\hline 19 & A19Vehicle & Vehicles \\
\hline 20 & A 200 thM ach & Oth Machinery \\
\hline 21 & A $21 T \times t A p r l$ & Text \& Apparel \\
\hline 22 & A 220 th Ind & Other Industry \\
\hline 23 & A $23 E I G s W a t$ & Elec, Gas, Water \\
\hline 24 & A $24 C$ nstrct & Construction \\
\hline 25 & A 25 Trade & Trade \\
\hline 26 & A 26 Transp & Transport \\
\hline 27 & A $27 H$ otRest & Hotel \& Rest \\
\hline 28 & A 28 Perserv & Pers Services \\
\hline 29 & A 29 Com Serv & Commercial Srv \\
\hline 30 & A 30 P ubServ & Public Services \\
\hline 31 & $L 01 R U$ & Lab Rur Unsk \\
\hline 32 & $L O 2 R M$ & Lab Rur Mid $S k$ \\
\hline 33 & $L O 3 R H$ & $L a b R u r H i S k$ \\
\hline 34 & $L 04 U U$ & $L a b U r b U n s k$ \\
\hline 35 & $L O 5 U M$ & $L a b U r b M i d S k$ \\
\hline 36 & $L 06 U H$ & $L a b U r b H i S k$ \\
\hline 37 & Capital & Capital \\
\hline 38 & L and & Land \\
\hline 39 & $H H O 1 R F$ & H H Rur Farm \\
\hline 40 & H H $022 R S$ & HH Rur Self \\
\hline 41 & H H 03 R W & H H Rur Wage \\
\hline 42 & H H $04 R N$ & H H Rur Unemp \\
\hline 43 & H H $05 U$ F & H H Urb Farm \\
\hline 44 & H H 06 US & H H Urb Self \\
\hline 45 & H H $07 U$ W & H H Urb Wage \\
\hline 46 & H H $08 \mathrm{U} N$ & H H Urb Unemp \\
\hline 47 & E01State & E01State \\
\hline 48 & E 02 P rivD om & E 02 P rivD om \\
\hline 49 & E 03 PrivF or & E 03 PrivF or \\
\hline
\end{tabular}

